\title{
Elemental Chemical Composition, Size and Morphological Characterization of Individual Atmospheric Particles Within an Air Quality Program
}

\author{
R. Ramirez-Leal, ${ }^{*}$ H. Esparza-Ponce, ${ }^{* *}$ A. Varela-Sortillón, ${ }^{*}$ A. Astorga-Reyes, ${ }^{* A}$ A. Roman-B., ${ }^{*}$
}

*Centro de Estudios Superiores del Estado de Sonora,Ley Federal del Trabajo Final s/n Col. Apolo Hermosillo, Sonora, Mexico c.p. 83100

**Centro de Investigacion en Materiales Avanzados, S. C., Miguel de Cervantes Saavedra \#120, Complejo Industrial Chihuahua, Chihuahua, Chihuahua c.p. 31109

The characterization of individual particles was made by using TSP and PM10 filters from the Atmospheric Monitoring Program of Hermosillo, Sonora and the Transmission Electron Microscope Philips CM10 equipped with the EDS and EELS detectors.

The study was carried out from January to December 2007, using a section of $2 \mathrm{~cm}^{2}$ from the filters, which was placed in a test tube with isopropyl alcohol analytic grade J.T. Baker for 5 minutes, and then using a capillary, an aliquot was taken for its placement on the grid of the Transmission Electron Microscope.

We obtained 72 images of particles, both TSP and PM10, were it shows a great diversity of chainlike agglomerates or mass whose size is less than 0.2 micrometers. A diversity of aliphatic and aromatic HCs compounds are part of the composition of these agglomerates. Figure 1.

The results from the EDS showed a conformation of $\mathrm{Al}, \mathrm{Ca}, \mathrm{P}, \mathrm{Mg}, \mathrm{K}, \mathrm{Fe}, \mathrm{Cl}, \mathrm{Na}, \mathrm{Si}$, Ti and $\mathrm{S}$ (Figure 2); a microanalysis was developed by EELS, which detected U, C and Cs (Figure 3); but for $\mathrm{U}$ and especially $\mathrm{Cs}$, there is a low signal.

The elements found in the filters of TSP and PM10 indicate the importance of the individual characterization of atmospheric aerosols, because of the limited amount of information on the speciation and size of atmospheric particles, which allows us to have very valuable additional information on the potential action that these pollutants have.

\section{References}

[2]Berico, M., Luciani, A. and Formignani, M. 2007. Atmospheric aerosol in an urbana areameasurement of tsp and pm10 standards and pulmonary deposition assessment. Atmospheric Environment 31(21): 3659-3665.

[2]Giugliano, M., Lonati, G., Butelli, P., Romele, L. and Grosso, M. 2005. Fine particle (pm2.5pm1) at urban sites with different traffic exposure.Atmospheric Environment 39: 2421-2431

[2]Hueeglin,Ch., Gehrig, R., Baltensperger, U., Gysel, M.and Vonmont, H. 2005. Chemical characterization of pm2.5, pm10 and coarse particles at urban, near-city and rural sites in Switzerland. Atmospheric Environment 39: 637-651

[2] J.I. Goldstein et al., Scanning Electron Microscopy and X-ray Microanalysis, Plenum, New York, 1992. 
[2]Okada, K. and Kai, K. 2004. Atmospheric mineral particles collected at Quira in the Taklamakan Desert, China. Atmospheric Environment 38: 6927- 6935

[2]Ramírez-Leal, R., Esparza-Ponce, H. and Duarte-Moller, A. 2007. Characterization of inorganic atmospheric particles in air quality program with sem, tem and xas. Revista mexicana de Física 53(3): 102-107
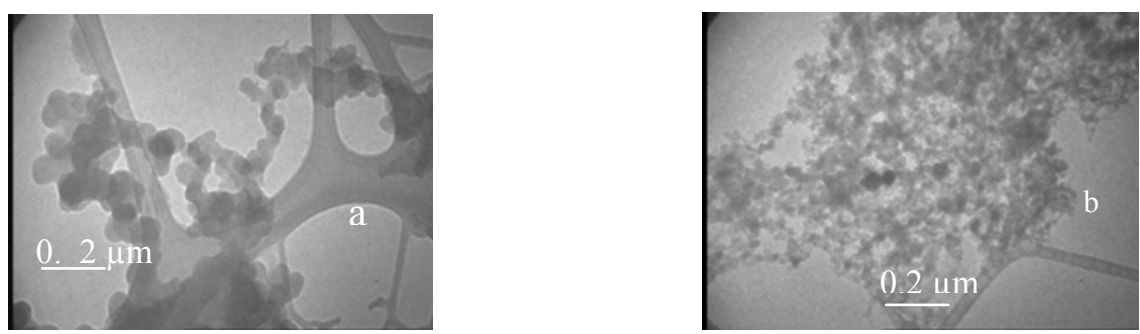

Figure 1.- Organic agglomerates in a) Chain-like and b) Mass obtained trough TEM

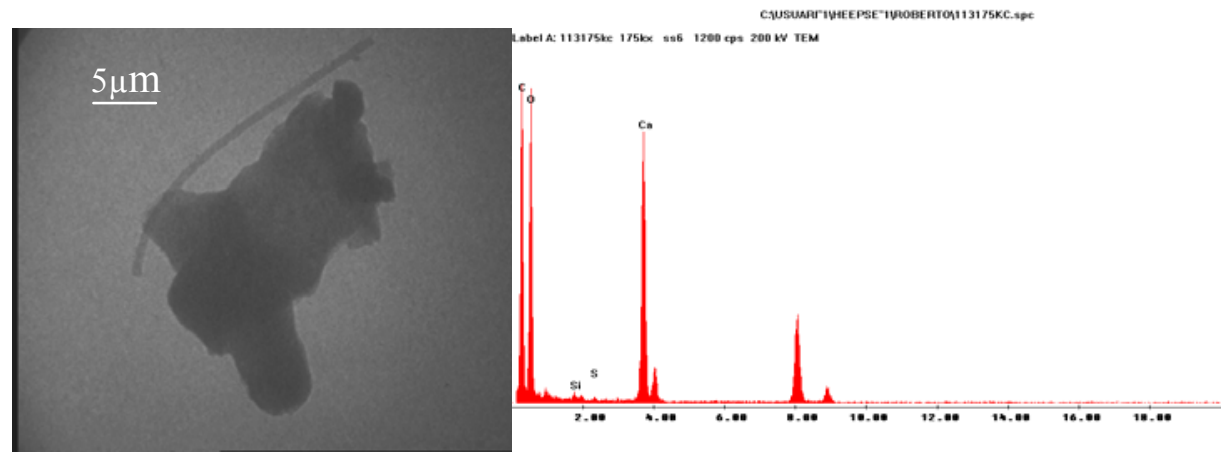

Figure 2.- Image and chemical composition of TSP obtained trought TEM
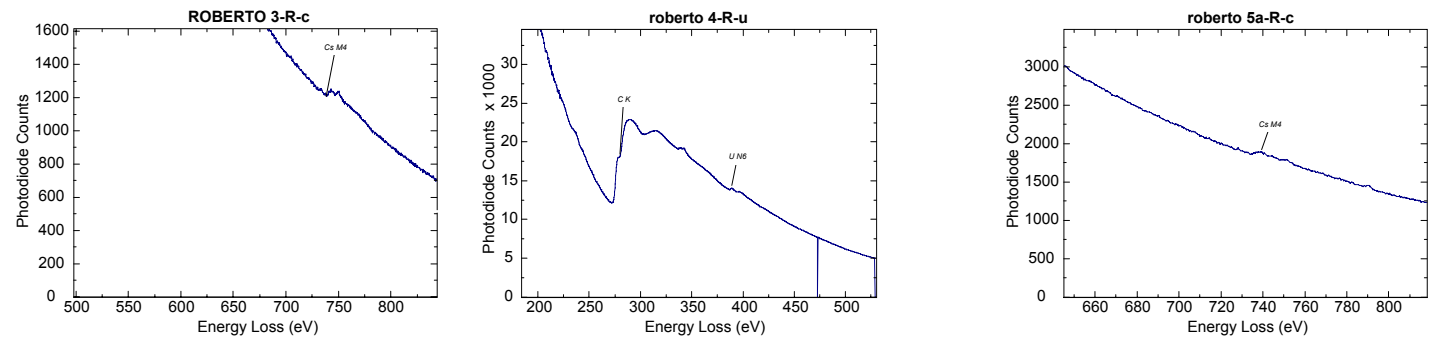

Figure 3.- EELS spectrum that shows the presence of $\mathrm{C}, \mathrm{U}$ and $\mathrm{Cs}$ in particles 